\title{
Betting the farm and playing it safe? Hyper-core self- evaluation in decisions when managers are winning and losing
}

\author{
Andreas Hönl ${ }^{1} \cdot$ Philip Meissner $^{2} \cdot$ Torsten Wulf $^{1}$
}

Received: 29 May 2019/Accepted: 1 November 2020/Published online: 18 November 2020

(C) The Author(s) 2020

\begin{abstract}
Core self-evaluation summarizes a decision maker's self-worth. This key personality trait has been shown to lead to extreme performance consequences of either winning or losing big. We suggest that these extreme performance outcomes may partly rest in how core self-evaluation affects executive's perception and evaluation of risk in choices under uncertainty. We conducted a choice experiment building on the original prospect theory experiments with 97 executives, in which we measured the effect of core self-evaluation on risk behavior. As a robustness test, we replicated and validated our findings with a larger sample of 111 executives. Building on the tenets of prospect theory, we show that decision makers with high levels of core self-evaluation are less loss averse. Surprisingly, this effect differs depending on whether gains or losses are highlighted in the decision. For gains, higher levels of core self-evaluation are associated with behaviors that are closer to risk neutrality. For losses, however, we find that higher levels of core self-evaluation further enhance the risk-seeking behavior of decision makers. These findings contribute towards understanding the effects of core self-evaluation in the work environment as well as in the decision process and provide an additional lens for studying how the personality of executives affects choices under uncertainty.
\end{abstract}

Keywords Core self-evaluation · Management · Decision making

Philip Meissner

pmeissner@escp.eu

1 Philipps-University Marburg, Universitätsstr. 24, 35037 Marburg, Germany

2 ESCP Business School Berlin, Heubnerweg 8-10, 14059 Berlin, Germany 


\section{Introduction}

Behavioral research in the management domain has embraced the concept of core self-evaluation (CSE) that captures executives' self-esteem, generalized selfefficacy, neuroticism, and locus of control as four core traits describing their individual personality structure (Hiller and Hambrick 2005; Judge et al. 2003; Simsek et al. 2010). In a management context, CSE has been shown to impact individual factors such as job satisfaction and job performance (Judge and Bono 2001), interpersonal factors such as leadership perception (Hu et al. 2012) as well as entrepreneurial orientation (Simsek et al. 2010) and performance (Hiller and Hambrick 2005).

While most studies in the field have argued for a positive effect of CSE in the organization (Erez and Judge 2001; Judge and Bono 2001; Tierney and Farmer 2002), other researchers suggest that very high levels of CSE, or so called hyperCSE, might reduce decision quality by inducing overconfidence and hubris, which is a state of extreme confidence triggered by internal and external stimuli (Hayward and Hambrick 1997). Such hyper-CSE has also been linked to extreme performance outcomes of either winning or losing big (Hayward and Hambrick 1997; Hiller and Hambrick 2005). We argue that these extreme performance effects of high level of CSE can partly be explained by linking CSE to executives' risk-taking behavior in decisions.

When making decisions, executives display a distinct risk-taking behavior (Sitkin and Pablo 1992; Sitkin and Weingart 1995), which has been shown to be affected by individual risk preferences (March and Shapira 1992) as well as by contextual factors such as the framing of the decision in terms of gains or losses (Tversky and Kahneman 1981). The latter effect has been famously conceptualized in Tversky's and Kahneman's prospect theory (Kahneman and Tversky 1979; Tversky and Kahneman 1992), which has emerged as the dominant theory for describing choices under uncertainty.

By integrating research on CSE and prospect theory, we suggest that the effect of CSE on executives' risk-taking behavior may differ depending on the decision context. Generally, CSE has been linked to overconfidence, the tendency to approach positive stimuli (Erez and Judge 2001; Simsek et al. 2010) and increased risk taking (Haleblian et al. 2007). However, prospect theory (Kahneman and Tversky 1979) suggests that these effects of CSE on executives' risk-taking behavior might differ in the domains of gains and losses as these contextual frames render decision-makers more risk averse or risk seeking, respectively. This may in turn help explain why CSE can have both, extremely positive and negative performance effects in organizations.

In this paper, we theorize and examine this relationship between CSE and risk behavior. Building on the tenets of prospect theory, we posit that CSE reduces loss aversion of decision makers in choices under uncertainty. The implications of this effect of CSE on executives' risk-taking behavior, however, will differ depending on the decision frame. In the domain of gains, the underweighting of uncertain outcomes with moderate and high probabilities is associated with more risk-averse 
decision-making behavior. In this domain, we argue that higher levels of CSE induce behavior closer to risk neutrality. In the domain of losses, however, the underweighting of uncertain outcomes with moderate and high probabilities makes decision-makers more risk seeking. Thus, we posit that in this domain higher levels of CSE tend to enhance risk-seeking behavior. Empirically, we test our hypotheses based on a study, in which we conducted choice experiments with 97 executives. For this, we created and pretested a setting closely resembling the approach of Tversky and Kahneman (1992), in which we added CSE as an additional psychological variable. Our results support our hypotheses. A second study involving 111 executives confirmed the robustness of our findings.

Our paper contributes to the literature on CSE in the management process (Hiller and Hambrick 2005; Simsek et al. 2010). Our theory and empirical results help explain divergent findings on the effect of CSE on executive risk-taking behavior and organizational performance by highlighting the divergent effects of CSE for different decision frames. With this, we provide an additional lens for studying how the personality of executives affects the strategy process of organizations. Our findings may thus provide a starting point for a more detailed examination of the antecedents and effects of personality in the strategy process and its aggregate influence on performance (Judge and Kammeyer-Mueller 2011). In addition, we provide a first detailed empirical account of the joint effects of contextual and personal factors on executives' risk-taking behavior in the decision-making process. This can inform the discussion on a more holistic and realistic conceptualization of choices under uncertainty as a foundation for behavioral research in the management domain (Gavetti 2012; Levinthal 2011).

The remainder of the paper is structured as follows. In the next section, we will introduce the theoretical arguments on the role of CSE in determining risk-taking behavior in situations of uncertainty. Then, we develop and test three hypotheses and close with the presentation of our results and a discussion of the implication of this study.

\section{Core self-evaluation and executives' risk behavior}

CSE comprises four common personality traits: self-esteem, generalized selfefficacy, locus of control, and emotional stability (Judge et al. 1997, 1998). More precisely, it views the overlap of these four factors as the common core (Judge et al. 2003). Self-esteem, which can be defined as one's general assessment of selfworthiness, is deeply rooted in cognitive, emotional, and behavioral processes (Blascovich and Tomaka 1991). The second personality trait, generalized selfefficacy, is an extension of Bandura's (1997) task-specific notion of self-efficacy. Judge et al. (1998, p. 19) describe it as one's appraisal of his or her "fundamental ability to cope with life's exigencies." The locus of control refers to the perception that one's actions can produce desired outcomes (internal locus of control), such that one is not at the mercy of fate (external locus of control) (Lefcourt 1991). The final component trait is emotional stability (the opposite of which is neuroticism), which reflects the tendency to stay calm and not be thrown off by irregular 
occurrences. In contrast, neurotic people are vulnerable to negative information (Larsen and Ketelaar 1991). The cognitive disposition summarized by CSE implies enduring manifestations of sensitivities toward positive or negative information. High levels of CSE are associated with strong approach temperaments, while low levels of CSE are associated with strong avoidance temperaments (Ferris et al. 2011). Such approach and avoidance temperaments can be viewed as an emotional fight or flight response, which in the case of approach temperaments lead to action while in the case of avoidance encourage inaction (Carver and Harmon-Jones 2009).

More recent research has increasingly studied the effect of CSE in an organizational context (for a review see: Chang et al. 2012). Judge and his colleagues have found CSE to improve job and life satisfaction (Judge et al. 1998, 2005) and lead to higher motivation and job performance (Erez and Judge 2001; Judge and Bono 2001). Also, CSE has been linked to lower stress levels (Luria and Torjman 2009) and improved career decision making (Fabio et al. 2012).

Hiller and Hambrick (2005) have argued that very high levels of CSE can induce quicker, more centralized decision making processes and more large-stake initiatives in the organization. However, such hyper-CSE may also facilitate overconfidence and hubris, which can create an extreme performance impact of either winning or losing big (Hiller and Hambrick 2005).

Both, overconfidence and hubris have been associated with differences in the risk-taking behavior of executives (Kahneman 2012). Thus, we argue that extreme performance outcomes of hyper-CSE may be partly explained by the influence of CSE on executives' risk-taking behavior. Differences in individual risk-taking behavior have been conceptualized by prospect theory, which has emerged as the dominant perspective for studying decision-making under risk and uncertainty. Thus, divergent effects of hyper-CSE on executives' risk-taking behavior might best be analyzed in the context of this theory (Kahneman and Tversky 1979; Tversky and Kahneman 1992).

\subsection{The tenets of prospect theory}

According to prospect theory, decision makers evaluate risky prospects in relation to a certain reference point, which divides outcomes into gains and losses. This creates two different domains that either describe gains (domain of gains) or losses (domain of losses) to the decision maker (Kahneman and Tversky 1979; Tversky and Kahneman 1992). In general, following classic decision theory, decision makers can be either risk seeking, risk averse or risk neutral. Risk aversion describes the tendency to prefer a certain outcome over a gamble that is of equal or eventually higher expected value. The rejection of a certain outcome in favor of a gamble, that has an equal or eventually even a lower expected value, is called risk seeking. When decision makers are risk neutral, they are indifferent between the certain outcome and the corresponding gamble of equal expected value (Kahneman and Tversky 1984). For determining preference values, cumulative prospect theory introduces cumulative decision weights. These decision weights are determined by a rankdependent or cumulative functional that transforms cumulative rather than outcome probabilities. Thus, the decision weight of an outcome is the marginal weight 
contribution of its outcome-probability to its rank and is, therefore, the difference between two weights of ranks (Wakker 2010). It measures the impact of outcomes on the preference for prospects and not the likelihood of such outcomes (Kahneman and Tversky 1984).

With regard to the values of uncertain outcomes, prospect theory describes two phenomena: loss aversion, i.e., an observed asymmetry between losses and gains with losses looming larger than corresponding gains, and diminishing sensitivity, i.e., decreasing marginal value of gains and losses, respectively. These characteristics can be expressed using the following two-part power function (Tversky and Kahneman 1992):

$$
v(x)=\left\{\begin{array}{l}
x^{\alpha}, \text { if } x \geq 0 \\
-\lambda \times(-x)^{\beta}, \text { if } x<0
\end{array}\right.
$$

with $\alpha, \beta>0$ and $\lambda>1$.

The parameter $\lambda$ represents the effect of constant relative loss aversion, while the parameters $\alpha$ and $\beta$ represent diminishing sensitivity if they lie between 0 and 1 (Tversky and Kahneman 1992). The concavity of the value of gains describes risk aversion, while the convexity of the value of losses describes risk seeking behavior (Kahneman and Tversky 1984).

Additionally, Tversky and Kahneman (1992) observe that decision makers tend to overweight low probabilities and underweight moderate and high probabilities of uncertain outcomes. The underweighting of moderate and high probabilities in the domain of gains contributes to risk aversion by reducing the attractiveness of positive gambles, whereas in the domain of losses, it contributes to risk seeking by attenuating the aversiveness of negative gambles (Tversky and Kahneman 2000). This is reflected in the following weighting functions which Tversky and Kahneman (1992) fitted for gains $\left(w^{+}\right)$and losses $\left(w^{-}\right)$from experimental data on individual choice:

$$
\begin{aligned}
& w^{+}(p)=\frac{p^{\gamma}}{\left(p^{\gamma}+(1-p)^{\gamma}\right)^{1 / \gamma}} \\
& w^{-}(p)=\frac{p^{\delta}}{\left(p^{\delta}+(1-p)^{\delta}\right)^{1 / \delta}}
\end{aligned}
$$

with $\gamma, \delta>0$.

The parameters $\gamma$ and $\delta$ determine the curvature of the weighting function for gains and losses, respectively. In summarizing the characteristics of the value and the weighting functions, Tversky and Kahneman (1992) derive a fourfold pattern: people tend to adopt risk-averse behaviors for gains and risk-seeking behaviors for losses with moderate and high probabilities. For gains and losses with low probabilities, however, these behaviors are reversed. Both parameters $\gamma$ and $\delta$ must lie between 0 and 1 in order to yield the inverse s-shaped graph that represents the fourfold pattern. The closer the parameters are to 1 , the less the curves are bent, which implies less pronounced risk-averse and risk-seeking behaviors. 


\subsection{The effect of hyper-core self-evaluation on risk behavior}

To theorize the effect of hyper-CSE on risk-taking behavior in the context of prospect theory, its influence has to be considered for both the value of risky prospects and their corresponding decision weights, based on which the respective prospects are evaluated.

\subsubsection{Hyper-CSE and the value of risky prospects}

Personality factors and individual cognition have been shown to affect risk-taking behavior (Hodgkinson and Healey 2008; Sitkin and Weingart 1995). We suggest that CSE as a stable personality trait that summarizes a decision maker's self-worth (Judge et al. 1997) may be a crucial personality trait that shapes decision makers' risk preference. Prior research has shown that managers who display high CSE tend to lead their organization in a more entrepreneurial fashion (Simsek et al. 2010), which includes more innovativeness, proactiveness and risk taking (Miller 1983). Other research has hinted into a similar direction concerning the relationship between CSE and risk taking. Hiller and Hambrick (2005) argued that hyper-CSE individuals tend to be more overconfident (Hiller and Hambrick 2005), which has been linked to excessive risk taking in the context of new market entrants (Camerer and Lovallo 1999). This inclination towards more risk taking and overconfidence generally reduces the loss aversion of executives (Camerer and Lovallo 1999). Based on an overestimation of skill (Hiller and Hambrick 2005), high-CSE individuals should trigger emotional approach or avoidance temperaments to pursuing the possibility of winning or evading the odds of losing, respectively (Elliot and Thrash 2002). Thus, as a baseline hypothesis, we posit that the higher the decision makers' CSE, the less pronounced their tendency toward loss aversion will be. We argue:

Hypothesis 1: Higher levels of core self-evaluation are associated with lower levels of loss aversion among executives.

Formally stated, the CSE level (CSE) has an additive effect on the loss-aversion factor $\lambda$. CSE can take on values between 1 and 7 (see Main Study in the Research Design section). This is reflected in the following value function:

$$
v(x, \text { cse })=\left\{\begin{array}{l}
x^{\alpha}, \text { if } x \geq 0 \\
-(\lambda+\pi \times \text { cse }) \times(-x)^{\beta}, \text { if } x<0
\end{array}\right.
$$

with $\pi<0 ; 1 \leq$ cse $\leq 7$.

\subsubsection{Hyper-CSE and decision weights in the domain of gains}

The general effect of CSE on loss aversion, however, has different implications for executives' risk-taking behavior in the domains of gains and losses. In the domain of gains individuals are generally characterized by risk aversion (for prospects with moderate and high probabilities) (Kahneman and Tversky 1979). Prior research indicates that high-CSE individuals are keen to approach positive stimuli (Erez and 
Judge 2001). They are likely to overestimate their own capabilities based on high self-esteem and overconfidence (Erez and Judge 2001; Hiller and Hambrick 2005) and neglect external disturbing factors due to their internal locus of control (Anderson 1977). Thus, they tend to have an overly optimistic perception of the situation (Trepel et al. 2005). This is likely to reduce the risk aversion that individuals tend to show in gain frames as they appreciate the opportunity of winning and generally rate probabilities of gains as positive outcomes higher (Kray and Galinsky 2003; Trepel et al. 2005). This suggests that the higher the decision makers' CSE, the more the absolute value of achieving a gain will outweigh the absolute value of avoiding a loss, which is reflected in higher decision weights in the domain of gains. These higher decision weights mean at the same time that decision makers' level of risk aversion is reduced which leads them to show a behavior which is closer to risk neutrality. We posit:

Hypothesis 2: Higher levels of core self-evaluation are associated with higher decision weights in the domain of gains.

The weighting function that describes this hypothesis needs to reflect an elevation of the curve indicating the general inclination toward risk-avoiding or risk-taking behavior based on CSE levels. This property is expressed by a positive parameter $\varepsilon^{+}$, which is multiplied with the CSE level (cse). Building on an equation developed by Lattimore et al. (1992) and applied by other scholars (e.g. Kilka and Weber 2001; Trepel et al. 2005; Tversky and Fox 1995), the weighting function reflecting our hypothesis can be described as follows:

$$
w^{+}(p, \text { cse })=\frac{\varepsilon^{+} \times \operatorname{cse} \times p^{\gamma}}{\varepsilon^{+} \times \operatorname{cse} \times p^{\gamma}+(1-p)^{\gamma}}
$$

with $\varepsilon^{+}>0$.

\subsubsection{Hyper-CSE and decision weights in the domain of gains}

In the domain of losses, high-CSE individuals should similarly display excess overconfidence (Hiller and Hambrick 2005), which induces changes in the assessment of risk (Camerer and Lovallo 1999; Kahneman and Lovallo 1993). Therefore, individuals with high CSE should rate probabilities of negative outcomes lower. They will feel less fear of losing something, which yields lower decision weights in the loss domain. However, in the domain of losses individuals are generally characterized by risk-seeking behavior (for higher probabilities) (Kahneman and Tversky 1979). Thus, lower decision weights of high-CSE individuals in the loss domain will further increase their risk-seeking behavior inducing more riskseeking decision-making behavior. We suggest:

Hypothesis 3: Higher levels of core self-evaluation are associated with lower decision weights in the domain of losses.

With regard to the weighting function for losses, note that the CSE variable is ranked in reverse order, as increasing CSE should deflate decision weights. This translates into the following equation: 


$$
w^{-}(p, \text { cse })=\frac{\varepsilon^{-} \times \operatorname{cse} \times p^{\delta}}{\varepsilon^{-} \times \operatorname{cse} \times p^{\delta}+(1-p)^{\delta}}
$$

with $\boldsymbol{\varepsilon}^{-}>0$.

\section{Research design}

To test the influence of CSE on individual risk-taking behavior in the context of prospect theory, we designed a research setting that closely resembled the approach adopted by Tversky and Kahneman (1992). This allowed us to capture executives' risk preferences with regard to the value of uncertain prospects as well as their respective decision weights, while simultaneously integrating and studying the role of CSE.

Our research proceeded in two steps. In a pretest, we developed a short variant of the original choice experiments designed by Tversky and Kahneman (1992). Shortening the original choice experiments seemed necessary to motivate executives instead of students (Tversky and Kahneman 1992) — to participate in our study. In our main study, we applied this short variant with a sample of executives to test our hypotheses on the effects of CSE on risk-taking behavior.

\subsection{Pretest: validation of our risk behavior choice experiment}

To develop a short variant of the original choice experiments designed by Tversky and Kahneman (1992), we followed a two-step process. First, we conducted a pretest with two independent samples of graduate students participating in a management program (pretest group 1: $n_{1}=26$ students; pretest group 2: $n_{2}=61$ students). The questions presented to the pre-test participants were identical to those used in the choice experiments conducted by Tversky and Kahneman (1992). Specifically, participants were presented with 28 prospects in the gain domain and 28 prospects in the loss domain, e.g. the opportunity of winning EUR 50 with a probability of $10 \%$ (or of winning nothing with a $90 \%$ probability). Additionally, the expected value of the prospects as well as an ascending series of sure outcomes were displayed. The sure outcomes were logarithmically spaced between the lowest and the highest outcomes of the prospects (i.e., between EUR 0 and EUR 50 in our example). In the gain domain, respondents had to indicate the lowest sure outcome that they preferred more than playing the gamble, while in the loss domain, participants were asked to pick the highest sure loss they were willing to bear to avoid playing the gamble. We used these values as certainty equivalents (see Table 4 in the appendix for an overview of the prospects which we used in the prestudy).

The relation of the certainty equivalents indicated by the respondents to the prospects' maximum outcomes reflects individual decision weights (e.g., EUR $10 /$ EUR $50=0.2$ ). For prospects with equal outcome probabilities, we averaged the decision weights. This allowed us to accumulate a data series comprising decision 
weights and outcome probabilities, and to produce a distinct weighting function for each participant.

Additionally, participants in pretest group 2 were presented with eight mixed prospects with equal chances of losing a given amount of money or winning an amount that they had to specify (e.g. a 50\% chance to either lose EUR 50 or to win EUR $x$ ). For each of these mixed prospects, the respondents were asked to indicate the value for $x$ that made the gamble acceptable to them. The default losses in the series of prospects increased systematically to account for the effect of diminishing sensitivity. By matching the amount of money that the respondents required if they won to compensate for the potential loss to the default negative outcome, we can derive how the individuals valued gains compared to losses. By dividing the (default) negative and (stated) positive outcomes of all mixed prospects, the lossaversion factor can be calculated for each respondent.

For both groups, we used regression analyses to estimate the parameters of the weighting functions (2) and (3) for gains and losses, respectively. These analyses confirmed Tversky and Kahneman's results, i.e., the characteristics of the weighting functions for gains and losses are in line with prospect theory. For the pretest group 1 , we estimated parameters of the weighting functions of $\gamma=0.73(p<0.001)$ compared to 0.61 in Tversky and Kahneman's (1992) study-and $\delta=0.61$ $(p<0.001)$ compared to 0.69 (Tversky and Kahneman 1992) for gains and losses, respectively. For pretest group 2, we were not only able to estimate the parameters of the weighting functions (2) and (3), but also the parameter for loss aversion in the value function (1). The results are similar for the weighting functions $(\gamma=0.74$, $p<0.001 ; \delta=0.58, p<0.001)$. In terms of the value function, the parameters $\lambda=2.62(p<0.001)$ compared to 2.25 in Tversky and Kahneman's (1992) study and $\alpha=\beta=0.95$ ( $p<0.001)$ compared to 0.88 (Tversky and Kahneman 1992) also fit prospect theory.

In a second step, we developed a short variant of the choice experiments, which contained only 15 prospects in the gain domain and 15 prospects in the loss domain. To arrive at this short variant, we eliminated 13 prospects in the gain domain and 13 prospects in the loss domain which only differ in the prospect's value, but not in the respective probabilities from one of the remaining prospects. For example, Tversky and Kahneman (1992) test risk preferences for two prospects with exactly the same probabilities, but different certain outcomes, such as 0, 50 and 50, 100. As they afterwards aggregate the results of all transformed prospects (as long as the outcome probabilities are equal), we forgo this differentiation (see Table 4 in the appendix for an overview of the prospects which were used in the short variant). The short variant of the choice experiment also contained the eight mixed prospects with equal chances of losing a given amount of money or winning an amount that had been applied in pretest group 2 to allow us to estimate the parameters of the value function.

The shortened version of the original prospect theory choice experiments yielded results that were in line with those of Tversky and Kahneman (1992) as well as with our pre-study. More precisely, the parameters of the weighting function of $\gamma=0.78$ $(p<0.001)$ and $\delta=0.64(p<0.001)$ for gains and losses, respectively, result in an inverse $\mathrm{S}$-shaped functions that follow the fourfold pattern of prospect theory-the 
overweighting of low probabilities and the underweighting of high probabilities. In the value function, we find a clear trend of loss aversion with $\lambda=2.62(p<0.001)$ and decreasing marginal values of gains and losses reflected by $\alpha=\beta=0.95$ $(p<0.001)$.

\subsection{Main study: CSE and risk behavior choice experiment}

\subsubsection{Sample}

To attain a well-balanced sample for our choice experiment, we selected nine different industries. In each industry, we addressed employees from several companies at different hierarchical levels. In the end, 97 executives from different companies and across various industries, such as professional services, financial institutions, and manufacturing, participated in the choice experiment. The majority of the participants were male $(75 \%)$ and ranged from 25 to 40 years of age. Thus, the sample was skewed towards male participants reflecting the low proportion of female executives in organizations (Thornton 2016). Most respondents held a master's degree or higher (91\%) and had a business or economics background $(82 \%)$. About one half (54\%) of the participants had been with their companies for 2-5 years, $32 \%$ had been with their companies for less than 2 years, and $14 \%$ had been with their companies for at least 5 years. $60 \%$ were specialists without direct reports. The other $40 \%$ were senior managers (25\%) and company executives $(15 \%)$

\subsubsection{Procedure}

The choice experiment was computer based and contained a questionnaire with three sections that all participants had to complete. The first section addressed risk preferences. We applied the short variant of the choice experiments originally developed Tversky and Kahneman (1992). Similar to the pretest setting described above, participants were presented with 15 prospects in the gain domain and 15 prospects in the loss domain in a randomized order. In addition to the prospects' contingent outcomes and probabilities, the expected value of the prospects as well as an ascending series of sure outcomes were displayed. Moreover, the median of the sure outcomes equaled the expected value of the prospects in order to avoid distortion toward risk-avoiding or risk-seeking tendencies. In the gain domain, respondents had to indicate the lowest sure outcome that they preferred more than playing the gamble. In the loss domain, participants were asked to pick the highest sure loss they were willing to bear in order to avoid playing the gamble.

Furthermore, the respondents were presented with eight mixed prospects with equal chances (e.g., a $50 \%$ chance to either lose EUR 50 or win EUR $x$ ). The values of the prospects rose systematically. For each of these mixed prospects, the respondents were asked to indicate the value for $x$ that made the gamble acceptable to them. The greater the value respondents indicated for $x$, the more they valued losses compared to gains, which is an indication of loss aversion. 
In section two of the questionnaire, we assessed the participants' CSE levels. To measure CSE, we used a well-validated 12-item construct developed by Judge et al. (2003) and a 7-point Likert-scale. As a measure of CSE, we used the mean value of the 12 items where 7 indicates the highest CSE level. The full questionnaire can be found in Table 5 in the appendix. In the final section of the questionnaire, the respondents provided demographic information as well as information on their education and work experience.

\section{Results}

In our sample, the respondents had CSE scores between 3.42 and 7.00 with a mean score of 5.45 and a median of 5.50. As the mean is smaller than the median value, this indicates a negatively skewed sample distribution. These results are in line with the findings of Hiller and Hambrick (2005), who show that executives generally tend to display high levels of CSE. However, given the standard deviation of 0.70, we find sufficient variance in our sample to support the assumption that decision makers vary sufficiently in their personal characteristics to show differences in their risk preferences and behavior (Hambrick and Mason 1984).

\subsection{Does core self-evaluation affect the value function and loss aversion?}

To test our hypotheses, we first analyze the effect of loss aversion, i.e., a decision maker's inclination to attach higher absolute values to losses than to gains. As Tversky and Kahneman show (1992), this effect amounts to the factor of $\lambda=2.25$, which implies that losses loom twice as much as gains. To examine the influence of individual cognition on loss aversion, we linked the respondents' CSE levels to their evaluations of losses compared to gains. To do so, we used a linear regression model. For the mean CSE in our sample, we found a predicted loss aversion of 2.12, which is almost identical to that of Tversky and Kahneman (1992). However, our findings indicate that loss aversion decreases (increases) significantly as CSE rises (declines). The estimated parameter for CSE equals $-0.41(p<0.001)$. Therefore, with every step on the CSE scale, the loss-aversion factor decreases by this amount. This finding supports our hypothesis that CSE reduces a decision maker's loss aversion. The application of the estimation to our sample data yields distinct degrees of loss aversion ranging from 2.95 for the lowest CSE of 3.42-1.49 for the highest CSE of 7.00. This result implies that higher CSE levels lead to a more balanced evaluation of losses and gains. Hence, the effect of loss aversion persists, but its magnitude is significantly dependent on CSE (see Fig. 1).

Furthermore, we incorporated CSE as an additional input factor in Tversky and Kahneman's (1992) value function. A comparison of the new fitted model in Table 1 to our initial results (excluding CSE) confirms the negative impact of CSE on loss aversion. The extended non-linear regression model not only yields robust parameters for loss aversion $(\lambda=5.27, p<0.001)$ and diminishing sensitivity $(\alpha=\beta=0.95, p<0.001)$, but it also shows a highly significant negative effect of CSE on loss aversion $(\pi=-0.48, p<0.001)$ yielding support for our first 


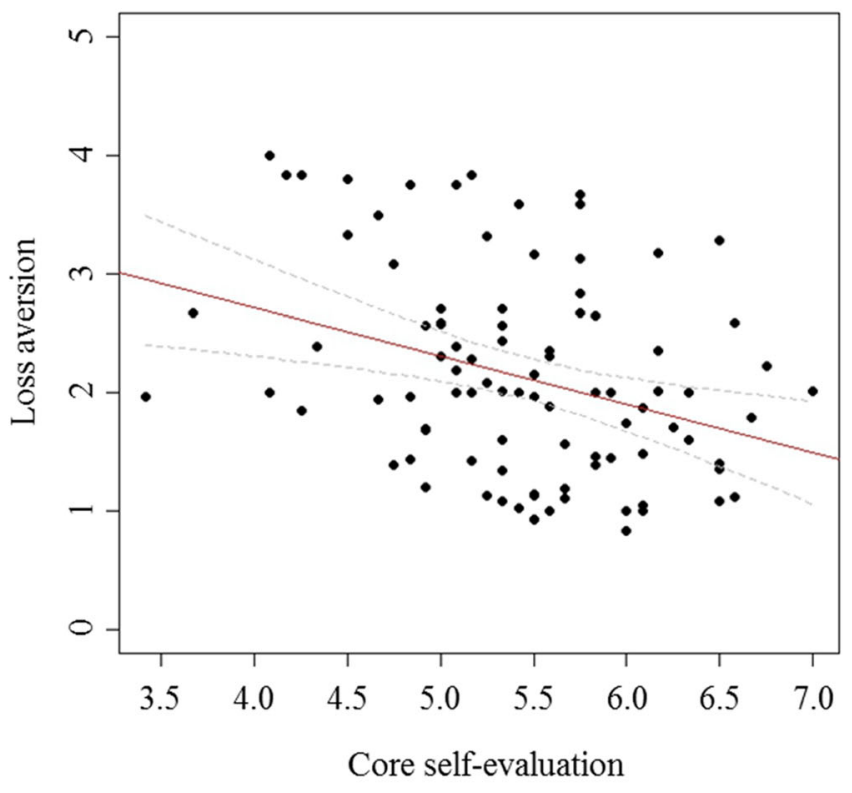

\begin{tabular}{lllll}
\hline \hline Coefficients: & Estimate & Std. error & t value & p value \\
\hline (Intercept) & 4.338 & 0.645 & 6.730 & $<0.001$ \\
Core self-evaluation & -0.407 & 0.117 & -3.465 & $<0.001$ \\
\hline
\end{tabular}

Residual standard error: 0.801 on $95 \mathrm{DoF}$

Multiple R-squared: 0.112, adjusted R-squared: 0.103

F-statistic: 12.01 on 1 and 95 DoF, p-value: $<0.001$

Note: Loss aversion refers to the parameter $(\lambda+\pi * c s e)$ in the value function (4)

Fig. 1 Study 1: test of loss aversion

hypothesis ${ }^{1}$. In other words, people with high CSE have a lower tendency toward loss aversion than low-CSE individuals. In our tests, we also controlled for various factors, such as gender and age as well as educational and work background, none of which were significant. ${ }^{2}$

\subsection{Does core self-evaluation affect decision weights for gains and losses?}

To examine the role of CSE for the weighting of a prospect's contingent outcomes, we linked CSE to the decision weights in both domains. We included CSE as an

\footnotetext{
${ }^{1}$ We also tested for other effects of CSE, e.g., on diminishing sensitivity. The stated parameters remain unaffected. No other significant effects have been found.

${ }^{2}$ We have not included these results in our paper. However, they are available from the authors upon request.
} 
Table 1 Main study: comparison of regression models for loss aversion

\begin{tabular}{|c|c|c|c|c|}
\hline \multirow{2}{*}{$\begin{array}{l}\text { Model } \\
\text { Parameters }\end{array}$} & \multicolumn{4}{|c|}{$v(x)=\left\{\begin{array}{l}x^{\alpha}, \text { if } x \geq 0 \\
-\lambda \times(-x)^{\beta}, \text { if } x<0\end{array}\right.$} \\
\hline & Estimate & Std. error & $t$ value & $p$ value \\
\hline Loss aversion $(\lambda)$ & 2.623 & 0.669 & 3.920 & $<0.001$ \\
\hline Diminishing sensitivity $(\alpha=\beta)$ & 0.949 & 0.053 & 18.810 & $<0.001$ \\
\hline \multicolumn{5}{|c|}{ Residual standard error: 78.53 on $386 \mathrm{DoF}$} \\
\hline \multirow{2}{*}{$\begin{array}{l}\text { Model } \\
\text { Parameters }\end{array}$} & \multicolumn{4}{|c|}{$v(x$, cse $)=\left\{\begin{array}{c}x^{\alpha}, \text { if } x \geq 0 \\
-(\lambda+\pi \times \operatorname{cse}) \times(-x)^{\beta}, \text { if } x<0\end{array}\right.$} \\
\hline & Estimate & Std. error & $t$ value & $p$ value \\
\hline Loss aversion $(\lambda)$ & 5.266 & 1.328 & 3.966 & $<0.001$ \\
\hline Diminishing sensitivity $(\alpha=\beta)$ & 0.947 & 0.050 & 18.848 & $<0.001$ \\
\hline Core self-evaluation $(\pi)$ & -0.481 & 0.137 & -3.498 & $<0.001$ \\
\hline \multicolumn{5}{|c|}{ Residual standard error: 74.74 on $385 \mathrm{DoF}$} \\
\hline
\end{tabular}

additional input factor in our extended non-linear regression model based on research by Lattimore et al. (1992). The two-parametric function reflects two distinct characteristics of the weighting function. The first parameter, $\gamma$ or $\delta$, determines the curvature of the weighting function, while the second parameter, $\varepsilon^{+}$ or $\varepsilon^{-}$, determines its elevation depending on the CSE level (Trepel et al. 2005) in the domains of gains and losses, respectively. For the domain of gains, Table 2 compares the extended model with our estimation based on Tversky and Kahneman's (1992) original model. The results support our second hypothesis that higher CSE elevates decision weights independent of the outcome probabilities. The parameter $\gamma=0.79(p<0.001)$ confirms an inverse S-shaped weighting function in accordance with prospect theory. In addition, we find that the CSE parameter $\left(\varepsilon^{+}=\right.$ $0.16, p<0.001$ ) has a positive effect on decision weights. Respondents with higher levels of CSE generally attach higher decision weights to positive outcomes than those with low levels of CSE. Thus, high-CSE individuals tend to be less risk averse in the gain domain across all probability levels. This yields support for our second hypothesis.

Figure 2 contrasts weighting functions for three different CSE levels: the minimum, the median, and the maximum CSE scores in our sample. The bottom graph represents the most conservative risk-taking behavior for a CSE level of 3.42. The decision weights are lower than the respective outcome probabilities, as illustrated by the very low elevation of the curve. Therefore, low-CSE individuals are risk averse in the domain of gains-even for prospects with very low probabilities. In contrast, individuals with higher levels of CSE tend to show decision-making behavior closer to risk neutrality. As shown by the two upper graphs in Fig. 2 (CSE scores of 7 and 5.45, respectively), these two weighting functions fluctuate closely around the outcome probabilities. These results highlight 
Table 2 Main study: comparison of regression models for decision weights for gains

\begin{tabular}{|c|c|c|c|c|c|}
\hline \multirow{2}{*}{$\begin{array}{l}\text { Model } \\
\text { Parameters }\end{array}$} & \multicolumn{5}{|c|}{$w^{+}(p)=\frac{p^{\gamma}}{\left(p^{\gamma}+(1-p)^{\gamma}\right)} 1 / \gamma$} \\
\hline & \multicolumn{2}{|l|}{ Estimate } & Std. error & $t$ value & $p$ value \\
\hline$\gamma$ & 0.775 & & 0.010 & 79.050 & $<0.001$ \\
\hline \multicolumn{6}{|c|}{ Residual standard error: 0.112 on 1454 DoF } \\
\hline Model & & \multicolumn{4}{|c|}{$w^{+}(p, \mathrm{cse})=\frac{\varepsilon^{+} \times \operatorname{cse} \times p^{\gamma}}{\varepsilon^{+} \times \operatorname{cse} \times p^{\gamma}+(1-p)^{\gamma}}$} \\
\hline Parameters & & Estimate & Std. error & $t$ value & $p$ value \\
\hline$\gamma$ & & 0.791 & 0.015 & 53.570 & $<0.001$ \\
\hline Core self-evaluation $\left(\varepsilon^{+}\right)$ & & 0.157 & 0.003 & 51.790 & $<0.001$ \\
\hline \multicolumn{6}{|c|}{ Residual standard error: 0.112 on $1453 \mathrm{DoF}$} \\
\hline
\end{tabular}

the key role that individual cognition plays in decision making under risk. The curvature of the weighting function and its implications for individual risk-taking behavior are strongly influenced by CSE and the elevation of the weighting function.

We iterated the same approach for the loss domain. Table 3 shows the results of the comparison of both non-linear regression models of decision weights in the domain of losses. We find that low-CSE individuals attach higher decision weights to negative outcomes regardless of the outcome probabilities. The parameter $\delta=0.66(p<0.001)$ is robust and in line with prospect theory. In addition, we find that the CSE parameter $\left(\varepsilon^{-}=0.28, p<0.001\right)$ has a positive effect on decision weights. As we rank CSE in reverse order in the domain of losses, respondents with lower levels of CSE generally attach higher decision weights to negative outcomes than high-CSE individuals. Thus, we find that CSE is negatively correlated with decision weights in the domain of losses. This yields support for our third hypothesis.

As in the domain of gains, Fig. 3 shows weighting functions for three CSE levels in the domain of losses: the minimum, the median, and the maximum CSE scores in our sample. In this figure, the bottom graph represents individuals with a high CSE level of 7. The curvature indicates strong risk-seeking behavior, while for individuals with low levels of CSE (3.42), we find behavior patterns closer to risk neutrality. Thus, high CSE levels further strengthen risk-seeking behavior of individuals in the domain of losses.

\subsection{Robustness tests}

To further validate our results, we modified the empirical model for the domains of gains and losses to test for other potential effects of CSE on decision weights and to control for a number of other factors, including demographic characteristics, 


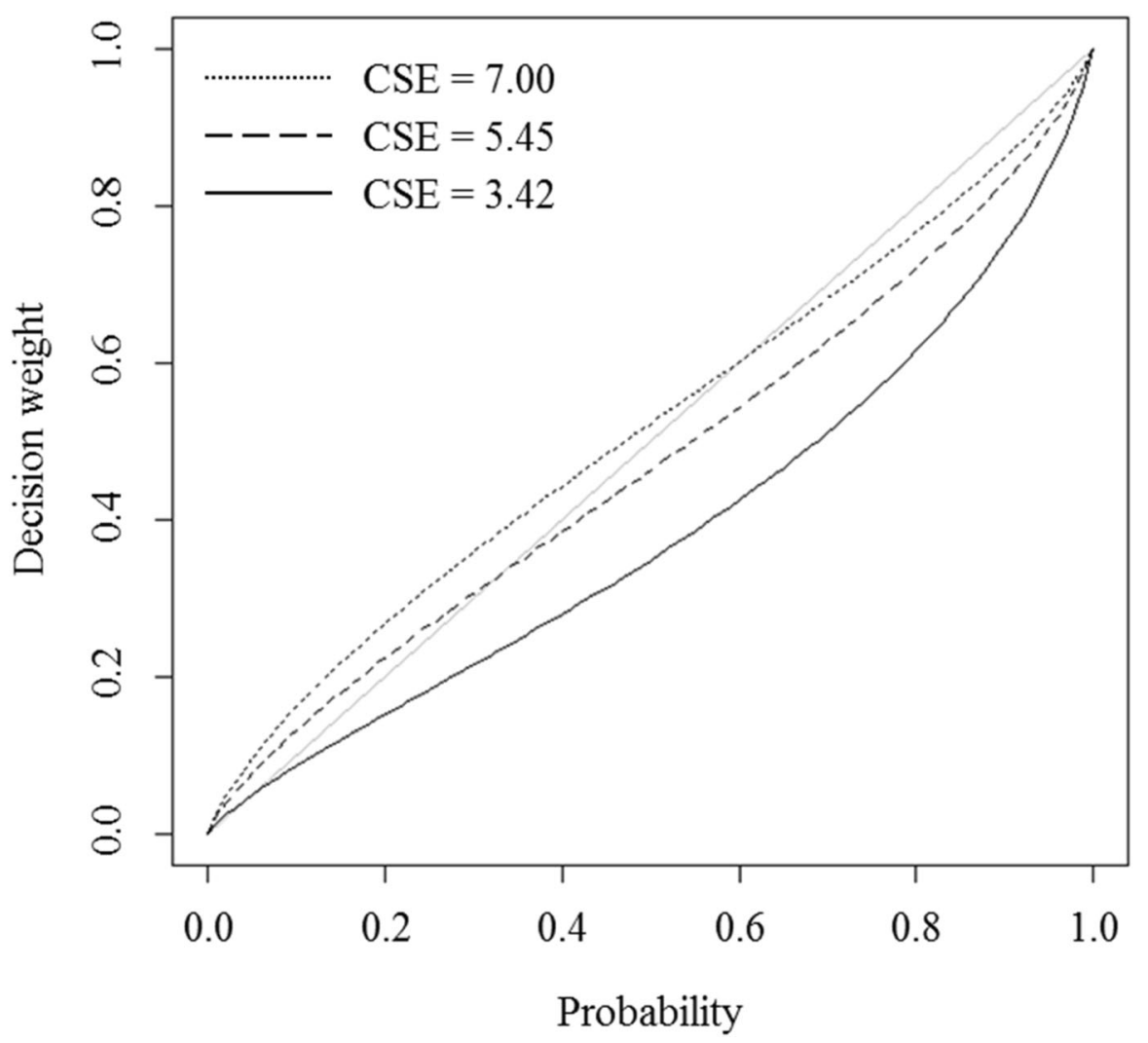

Fig. 2 Main study: weighting functions for different CSE levels in the gain domain

Table 3 Main study: comparison of regression models for decision weights for losses

\begin{tabular}{lllll}
\hline Model & $w^{-}(p)=\frac{p^{\delta}}{\left(p^{\delta}+(1-p)^{\delta}\right)} 1 / \delta$ & & \\
\cline { 2 - 5 } Parameters & Estimate & Std. error & $t$ value & $p$ value \\
\hline$\delta$ & 0.638 & 0.007 & 87.600 & $<0.001$
\end{tabular}

Residual standard error: 0.137 on $1454 \mathrm{DoF}$

\begin{tabular}{lllll}
\hline Model & \multicolumn{2}{l}{$w^{-}(p, \mathrm{cse})=\frac{\varepsilon^{-} \times \operatorname{cse} \times p^{\delta}}{\varepsilon^{-} \times \operatorname{cse} \times p^{\delta}+(1-p)^{\delta}}$} & & \\
\cline { 2 - 5 } Parameters & Estimate & Std. error & $t$ value & $p$ value \\
\hline$\delta$ & 0.657 & 0.015 & 45.29 & $<0.001$ \\
Core self-evaluation $\left(\varepsilon^{-}\right)$ & 0.278 & 0.007 & 41.97 & $<0.001$
\end{tabular}

Residual standard error: 0.143 on $1453 \mathrm{DoF}$ 


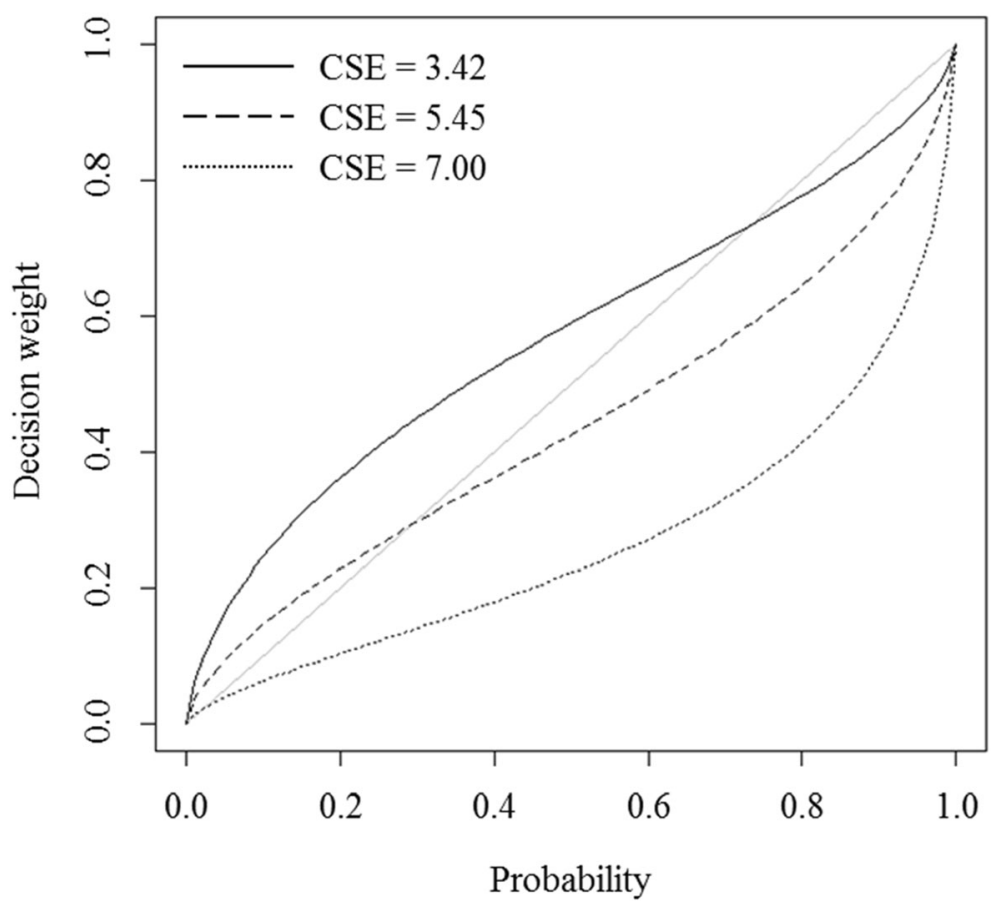

Fig. 3 Main study: weighting functions for different CSE levels in the loss domain

education, and work experience. We tested various functional forms and included other independent variables. The tests indicated that the findings presented above were robust. ${ }^{3}$

As a further robustness test we replicated the choice experiment in a second study with an ever larger number of executives. Specifically, we motivated 111 executives to participate in this study. Of these, $62 \%$ of participants were senior managers and $37 \%$ from middle management. The share of male $(55 \%)$ versus female $(45 \%)$ participants was balanced. Age ranged from 20 to 62 years. $73 \%$ of respondents held a bachelor's degree of higher. Their educational background was diverse with business $(35 \%)$ and engineering (13\%) being the top two fields of study. $64 \%$ of participants had been with their current employer for at least 5 years. Industry background was widely spread with professional services (23\%) and manufacturing/ production (11\%) as the largest segments. This replication study confirmed our findings from our main study regarding the relationship between core selfevaluation and decision weights for gains and losses. Specifically, in the domain of gains, the parameter value of $\gamma=0.64(p<0.001)$ confirms an inverse S-shaped weighting function in accordance with prospect theory. In addition, we find that $\operatorname{CSE}\left(\varepsilon^{+}=0.18, p<0.001\right)$ has a positive effect on decision weights offering further support for our hypothesis 2 . In the loss domain, the parameter value of

\footnotetext{
${ }^{3}$ We have not included these results in our paper. However, they are available from the authors upon request.
} 
$\delta=0.64(p<0.001)$ is in line with prospect theory. In addition, we find that the CSE $\left(\varepsilon^{-}=0.23, p<0.001\right)$ has a positive effect on decision weights yielding further support for our hypothesis 3 (Tables 4, 5 in appendix). The respective results are displayed in Tables 6 and 7 as well as in Figs. 4 and 5 in the appendix. Overall, results appear robust to alternative specifications and variable choices.

\section{Discussion}

High levels of CSE in executives have been linked to extreme performance impacts of either winning or losing big (Hiller and Hambrick 2005). We argue that such extreme outcomes may be partly explained by the influence of CSE on individual risk behavior, as high levels of CSE make decision makers less risk averse in the domain of gains and more risk seeking when losses are highlighted in decisions under uncertainty. When faced with gains, like in a growing business, executives seem to make better decisions as risk aversion is reduced and risk-taking behavior tends to be closer to risk neutrality. In situation that regularly emphasize losses, high CSE executives make more risk-seeking decisions, which can negatively affect performance. Our research thus suggests that risk-taking behavior might provide a crucial intermediary for explaining the effect of CSE in the decision-making process as well as outcomes on the organizational level such as performance.

These findings theoretically and empirically advance the discussion on the effect of executives' personality characteristics in the strategy process in general and CSE in particular (Erez and Judge 2001; Judge and Kammeyer-Mueller 2011; Simsek et al. 2010). From a theoretical point of view, we help explain divergent results in the field by introducing risk-taking behavior as an additional lens for studying the effect of CSE in the strategy process and by highlighting differences in the effect on CSE on risk-taking behavior depending on the decision framing (Hiller and Hambrick 2005). This can create a starting point for a more nuanced examination of the antecedents and effects of personality and its aggregate influence on performance (Judge and Kammeyer-Mueller 2011). In this way, our findings highlight a potential intermediary to the model of Hiller and Hambrick (2005), which can further bridge the gap between the micro and the macro dimension in the discussion on CSE.

Furthermore, our results provide one of the few empirical accounts that tests the effect of CSE in the decision-making process. They partly support the conceptual model of Hiller and Hambrick (2005) by showing that CSE affects individual choices under uncertainty, which has been shown to be a crucial element and result of the strategy process in organizations (Camerer and Lovallo 1999; Hodgkinson et al. 1999). As our results highlight that higher levels of CSE in executives are associated with higher risk-seeking behavior, they might also shed light on a potential underlying theoretical mechanism that can help explain the findings of Simsek et al. (2010). Specifically, the greater entrepreneurial orientation of organizations linked to high-CSE executives may be rooted in the risk-seeking behavior that CSE induces in executives. Further studying this relationship may thus provide interesting avenues for future research in the domain. 
Also, the findings reported in this paper contribute to a more fine grained understanding of risk-taking behavior in the context of the discussion on behavioral strategy (Powell et al. 2011). They suggest that risk-taking behavior is influenced by executives' cognitive disposition as well as decision framing, as posited by prospect theory (Kahneman and Tversky 1979; Tversky and Kahneman 1992). CSE as the perceived self-worth of executives can, thus, change the outcomes of decisions under uncertainty. These conclusions help explain prior empirical deviations from the fourfold pattern of prospect theory (Palich and Bagby 1995; Shyti 2013; Weinstein and Klein 1996). Also, they hint towards a more complex interplay of cognitive and contextual factors than conceptualized by prior research (Gavetti 2012; Sitkin and Pablo 1992).

\subsection{Limitations and future research}

As with all research our study has limitations, which can provide starting points for further advancing research in the domains of behavioral strategy and CSE. First, future research could target cultural aspects of CSE. Our choice experiments were conducted in a Western cultural setting. While we were able to obtain a sample of different industries, we could not control for the role of cultural differences in CSE. Scholars might want to conduct cross-cultural comparisons of CSE levels and their effect on risk behavior. Particularly, a comparison of Western and Asian cultures seems promising in this regard as the levels of CSE may differ significantly between cultural spheres (Hofstede and Hofstede 2001).

Second, our choice experiments utilized a shortened version of the original decision experiment by Tversky and Kahneman (1992). While the results of our pretest as well as the conceptual arguments provided above support the validity of the short decision experiment, additional research could build upon these findings and provide a broader account of the generalizability of the short version compared to the full version of Tversky and Kahneman (1992). In addition, a replication of the approach used in this study with the full version of the choice experiment in a management context could extend our findings based on an even more in-depth insight into the relationship of CSE and the specific decision weights in the domains of gains and losses.

\section{Conclusion}

This study provides theoretical insights into the effect of CSE in the strategy process of organizations. Building on the tenets of prospect theory, our findings suggest that CSE can positively and negatively affect decision depending on the decision frame. These findings can help explain the extreme performance outcomes of CSE in organizations and provides a more fine-grained understanding on the role of specific personality traits when executives in organizations make decisions under uncertainty. 
Open Access This article is licensed under a Creative Commons Attribution 4.0 International License, which permits use, sharing, adaptation, distribution and reproduction in any medium or format, as long as you give appropriate credit to the original author(s) and the source, provide a link to the Creative Commons licence, and indicate if changes were made. The images or other third party material in this article are included in the article's Creative Commons licence, unless indicated otherwise in a credit line to the material. If material is not included in the article's Creative Commons licence and your intended use is not permitted by statutory regulation or exceeds the permitted use, you will need to obtain permission directly from the copyright holder. To view a copy of this licence, visit http:// creativecommons.org/licenses/by/4.0/.

\section{Appendix}

See Figs. 4, 5 and Tables 4, 5, 6, 7.

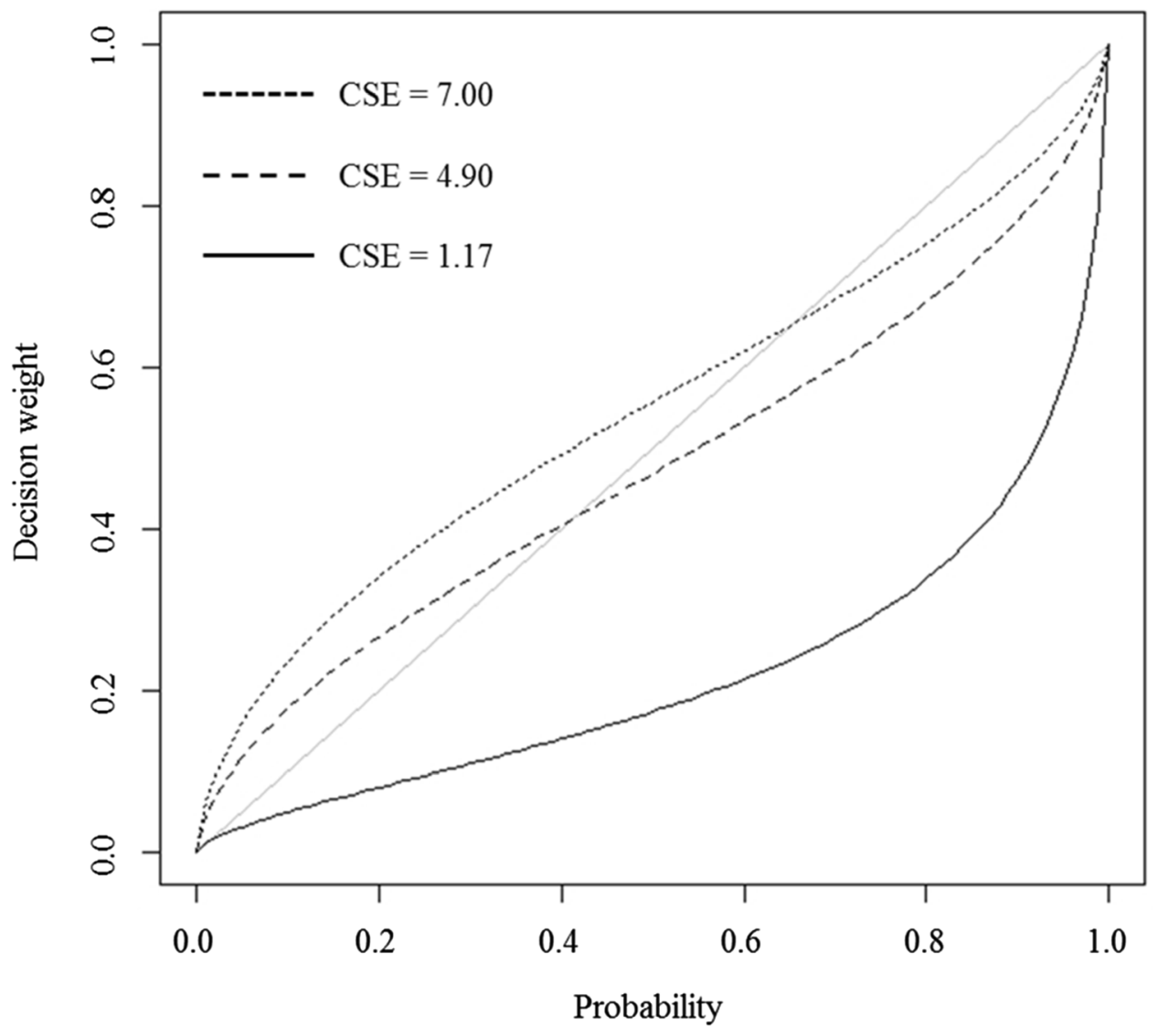

Fig. 4 Robustness test: weighting functions for different CSE levels in the gain domain 


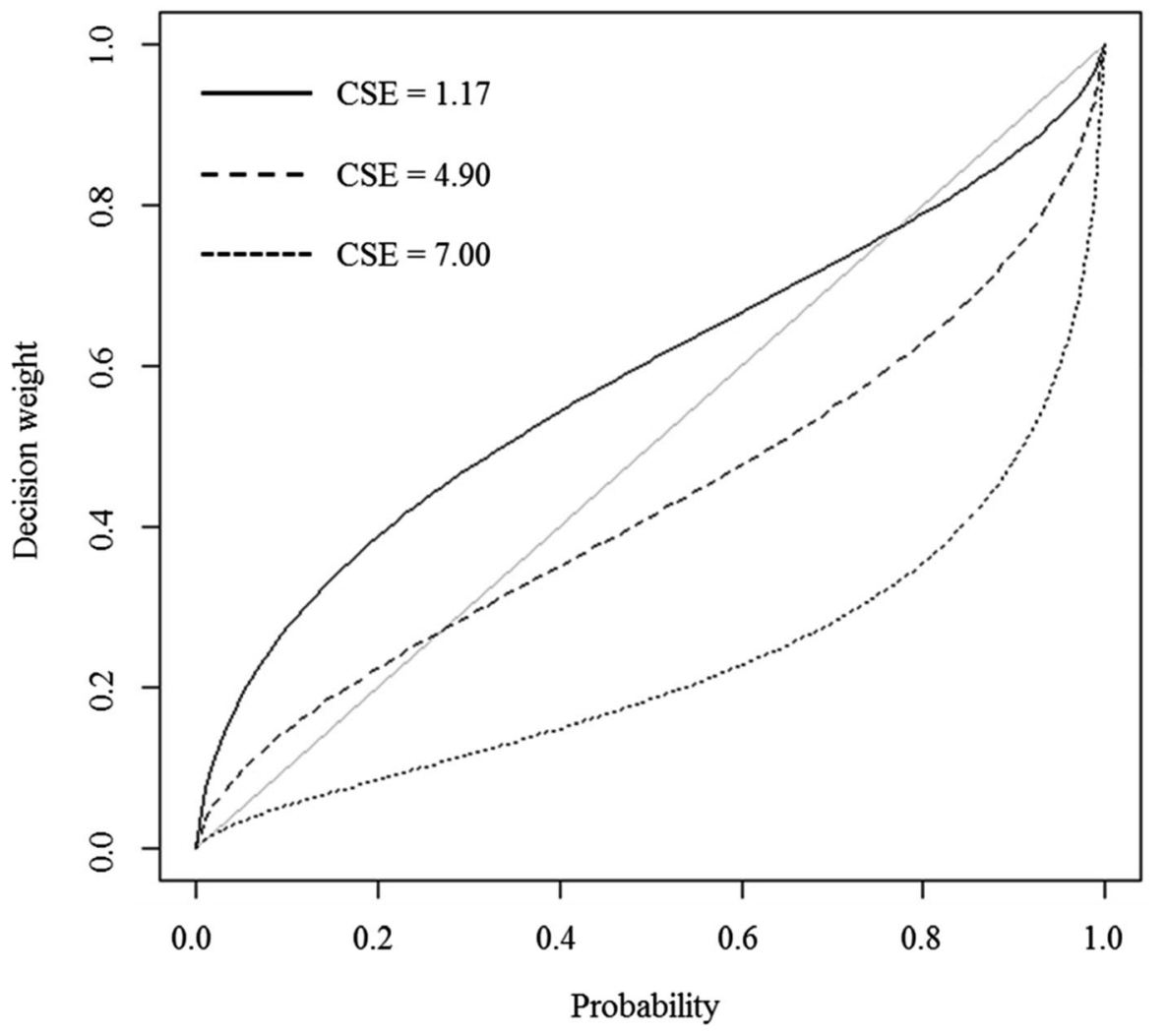

Fig. 5 Robustness test: weighting functions for different CSE levels in the loss domain 
Table 4 Risk-behavior questionnaire, adapted Tversky and Kahneman (1992)

\begin{tabular}{|c|c|c|c|c|c|c|c|c|c|}
\hline \multirow[b]{2}{*}{ Outcomes } & \multicolumn{9}{|c|}{ Probability } \\
\hline & 0.01 & 0.05 & 0.10 & 0.25 & 0.50 & 0.75 & 0.90 & 0.95 & 0.99 \\
\hline $\begin{array}{l}(0,50) \\
(0,-50)\end{array}$ & & & & & & & & & \\
\hline $\begin{array}{l}(0,100) \\
(0,-100)\end{array}$ & & & & & & & & & \\
\hline $\begin{array}{l}(0,200) \\
(0,-200)\end{array}$ & & & & & & & & & \\
\hline $\begin{array}{l}(0,400) \\
(0,-400)\end{array}$ & & & & & & & & & \\
\hline $\begin{array}{l}(50,100) \\
(-50,-100)\end{array}$ & & & & & & & & & \\
\hline $\begin{array}{l}(50,150) \\
(-50,-150)\end{array}$ & & & & & & & & & \\
\hline $\begin{array}{l}(100,200) \\
(-100,-200)\end{array}$ & & & & & & & & & \\
\hline
\end{tabular}

Item included in original questionnaire and in ours

Item included only in original questionnaire; not included in ours

The table shows prospects that participants were presented with. Each prospect is defined by contingent outcomes (e.g. a chance to win 0 or $50 €$ in the first line) and the probability of winning or losing (e.g. a 10 percent probability to win $0 €$ and, accordingly, a 90 percent chance of winning $50 €$ for the top left grey box). All grey and shaded boxes were prospects were used by Tversky and Kahneman (1992) as well as in our pretest. The prospects in dark grey were used in our final experiment

Table 5 Judge et al. (2003) core self-evaluation scale

\begin{tabular}{ll}
\hline Item & Statement \\
\hline 1 & I am confident I get the success I deserve in life \\
2 & Sometimes I feel depressed $(r)$ \\
3 & When I try, I generally succeed \\
4 & Sometimes when I fail I feel worthless $(r)$ \\
5 & I complete tasks successfully \\
6 & Sometimes I do not feel in control of my work $(r)$ \\
7 & Overall, I am satisfied with myself \\
8 & I am filled with doubts about my competence $(r)$ \\
9 & I determine what will happen in my life \\
10 & I do not feel in control of my success in my career $(r)$ \\
11 & I am capable of coping with most of my problems \\
12 & There are times when things look pretty bleak and hopeless to me $(r)$ \\
\hline
\end{tabular}

\footnotetext{
$r$ reverse-scored
} 
Table 6 Robustness test: comparison of regression models for decision weights for gains

\begin{tabular}{|c|c|c|c|c|c|}
\hline \multirow{2}{*}{$\begin{array}{l}\text { Model } \\
\text { Parameters }\end{array}$} & \multicolumn{5}{|c|}{$w^{+}(p)=\frac{p^{\gamma}}{\left(p^{\gamma}+(1-p)^{\gamma}\right)^{1 / \gamma}}$} \\
\hline & \multicolumn{2}{|l|}{ Estimate } & Std. error & $t$ value & $p$ value \\
\hline$\gamma$ & \multicolumn{2}{|l|}{0.693} & 0.010 & 75.250 & $<0.001$ \\
\hline \multicolumn{6}{|c|}{ Residual standard error: 0.151 on 1664 DoF } \\
\hline \multicolumn{2}{|l|}{ Model } & \multicolumn{4}{|c|}{$w^{+}(p, \operatorname{cse})=\frac{\varepsilon^{+} \times \operatorname{cse} \times p^{\gamma}}{\varepsilon^{+} \times \operatorname{cse} \times p^{\gamma}+(1-p)^{\gamma}}$} \\
\hline \multicolumn{2}{|l|}{ Parameters } & Estimate & Std. error & $t$ value & $p$ value \\
\hline$\gamma$ & & 0.640 & 0.014 & 45.220 & $<0.001$ \\
\hline Core self-evaluation $\left(\varepsilon^{+}\right)$ & & 0.180 & 0.004 & 44.040 & $<0.001$ \\
\hline \multicolumn{6}{|c|}{ Residual standard error: 0.153 on $1663 \mathrm{DoF}$} \\
\hline
\end{tabular}

Table 7 Robustness test: comparison of regression models for decision weights for losses

\begin{tabular}{|c|c|c|c|c|c|}
\hline \multirow{2}{*}{$\begin{array}{l}\text { Model } \\
\text { Parameters }\end{array}$} & \multicolumn{5}{|c|}{$w^{-}(p)=\frac{p^{\delta}}{\left(p^{\delta}+(1-p)^{\delta}\right)} 1 \delta$} \\
\hline & \multicolumn{2}{|l|}{ Estimate } & Std. error & $t$ value & $p$ value \\
\hline$\delta$ & \multicolumn{2}{|l|}{0.604} & 0.007 & 87.680 & $<0.001$ \\
\hline \multicolumn{6}{|c|}{ Residual standard error: 0.157 on 1664 DoF } \\
\hline \multicolumn{2}{|l|}{ Model } & \multicolumn{4}{|c|}{$w^{-}(p, \operatorname{cse})=\frac{\varepsilon^{-} \times \operatorname{cse} \times p^{\delta}}{\varepsilon^{-} \times \operatorname{cse} \times p^{\delta}+(1-p)^{\delta}}$} \\
\hline \multicolumn{2}{|l|}{ Parameters } & Estimate & Std. error & $t$ value & $p$ value \\
\hline$\delta$ & & 0.642 & 0.016 & 40.750 & $<0.001$ \\
\hline Core self-evaluation $\left(\varepsilon^{-}\right)$ & & 0.226 & 0.006 & 36.660 & $<0.001$ \\
\hline \multicolumn{6}{|c|}{ Residual standard error: 0.175 on 1663 DoF } \\
\hline
\end{tabular}

\section{References}

Anderson, C.R. 1977. Locus of control, coping behaviors, and performance in a stress setting: a longitudinal study. Journal of Applied Psychology 62 (4): 446.

Bandura, A. 1997. Self-efficacy: The exercise of control. London: Macmillan.

Blascovich, J., and J. Tomaka. 1991. Measures of self-esteem. In Measures of personality and social psychology attitudes, ed. J.P. Robinson, P.R. Shaver, and L.S. Wrightsman, 115-160. San Diego: Academic Press.

Camerer, C., and D. Lovallo. 1999. Overconfidence and excess entry: An experimental approach. The American Economic Review 89 (1): 306-318.

Carver, C.S., and E. Harmon-Jones. 2009. Anger is an approach-related affect: Evidence and implications. Psychological Bulletin 135 (2): 183.

Chang, C.-H., D.L. Ferris, R.E. Johnson, C.C. Rosen, and J.A. Tan. 2012. Core self-evaluations: A review and evaluation of the literature. Journal of Management 38 (1): 81-128. 
Di Fabio, A., L. Palazzeschi, and R. Bar-On. 2012. The role of personality traits, core self-evaluation, and emotional intelligence in career decision-making difficulties. Journal of Employment Counseling 49 (3): $118-129$.

Elliot, A.J., and T.M. Thrash. 2002. Approach-avoidance motivation in personality: Approach and avoidance temperaments and goals. Journal of Personality and Social Psychology 82 (5): 804.

Erez, A., and T.A. Judge. 2001. Relationship of core self-evaluations to goal setting, motivation, and performance. Journal of Applied Psychology 86 (6): 1270.

Ferris, D.L., C.R. Rosen, R.E. Johnson, D.J. Brown, S.D. Risavy, and D. Heller. 2011. Approach or avoidance (or both?): Integrating core self-evaluations within an approach/avoidance framework. Personnel Psychology 64 (1): 137-161.

Gavetti, G. 2012. PERSPECTIVE—-toward a behavioral theory of strategy. Organization Science 23 (1): 267-285.

Haleblian, J., L. Markoczy, and G. McNamara. 2007. The influence of core self-evaluation on risky strategic decisions. Paper presented at the Annual meeting of the Academy of Management, Philadelphia.

Hambrick, D.C., and P.A. Mason. 1984. Upper echelons: The organization as a reflection of its top managers. Academy of Management Review 9 (2): 193-206.

Hayward, M.L., and D.C. Hambrick. 1997. Explaining the premiums paid for large acquisitions: Evidence of CEO hubris. Administrative Science Quarterly 42: 103-127.

Hiller, N.J., and D.C. Hambrick. 2005. Conceptualizing executive hubris: The role of (hyper-) core selfevaluations in strategic decision-making. Strategic Management Journal 26 (4): 297-319.

Hodgkinson, G.P., and M.P. Healey. 2008. Cognition in organizations. Annual Review of Psychology 59: $387-417$.

Hodgkinson, G.P., N.J. Bown, A.J. Maule, K.W. Glaister, and A.D. Pearman. 1999. Breaking the frame: an analysis of strategic cognition and decision making under uncertainty. Strategic Management Journal 20 (10): 977-985.

Hofstede, G.H., and G. Hofstede. 2001. Culture's consequences: Comparing values, behaviors, institutions and organizations across nations. New York: Sage Publications.

Hu, J., Z. Wang, R.C. Liden, and J. Sun. 2012. The influence of leader core self-evaluation on follower reports of transformational leadership. The Leadership Quarterly 23 (5): 860-868.

Judge, T.A., and J.E. Bono. 2001. Relationship of core self-evaluations traits-self-esteem, generalized self-efficacy, locus of control, and emotional stability-with job satisfaction and job performance: A meta-analysis. Journal of Applied Psychology 86 (1): 80.

Judge, T.A., and J.D. Kammeyer-Mueller. 2011. Implications of core self-evaluations for a changing organizational context. Human Resource Management Review 21 (4): 331-341.

Judge, T.A., E.A. Locke, and C.C. Durham. 1997. The dispositional causes of job satisfaction: A core evaluations approach. Research in Organizational Behavior 19: 151-188.

Judge, T.A., E.A. Locke, C.C. Durham, and A.N. Kluger. 1998. Dispositional effects on job and life satisfaction: The role of core evaluations. Journal of Applied Psychology 83 (1): 17-34.

Judge, T.A., A. Erez, J.E. Bono, and C.J. Thoresen. 2003. The core self-evaluations scale: Development of a measure. Personnel Psychology 56 (2): 303-331.

Judge, T.A., J.E. Bono, A. Erez, and E.A. Locke. 2005. Core self-evaluations and job and life satisfaction: The role of self-concordance and goal attainment. Journal of Applied Psychology 90 (2): 257.

Kahneman, D. 2012. Thinking, fast and slow. London: Penguin Books.

Kahneman, D., and D. Lovallo. 1993. Timid choices and bold forecasts: A cognitive perspective on risk taking. Management Science 39 (1): 17-31.

Kahneman, D., and A. Tversky. 1979. Prospect theory: An analysis of decision under risk. Econometrica 47 (2): 263-291.

Kahneman, D., and A. Tversky. 1984. Choices, values, and frames. American Psychologist 39 (4): 341-350.

Kilka, M., and M. Weber. 2001. What determines the shape of the probability weighting function under uncertainty? Management Science 47 (12): 1712-1726.

Kray, L.J., and A.D. Galinsky. 2003. The debiasing effect of counterfactual mind-sets: Increasing the search for disconfirmatory information in group decisions. Organizational Behavior and Human Decision Processes 91 (1): 69-81.

Larsen, R.J., and T. Ketelaar. 1991. Personality and susceptibility to positive and negative emotional states. Journal of Personality and Social Psychology 61 (1): 132. 
Lattimore, P.K., J.R. Baker, and A.D. Witte. 1992. The influence of probability on risky choice: A parametric examination. Journal of Economic Behavior and Organization 17 (3): 377-400.

Lefcourt, H.M. 1991. Locus of control. In Measures of personality and social psychology attitudes, ed. J.P. Robinson, P.R. Shaver, and L.S. Wrightsman, 413-499. San Diego: Academic Press.

Levinthal, D.A. 2011. A behavioral approach to strategy—what's the alternative? Strategic Management Journal 32 (13): 1517-1523.

Luria, G., and A. Torjman. 2009. Resources and coping with stressful events. Journal of Organizational Behavior 30 (6): 685.

March, J.G., and Z. Shapira. 1992. Variable risk preferences and the focus of attention. Psychological Review 99 (1): 172.

Miller, D. 1983. The correlates of entrepreneurship in three types of firms. Management Science 29 (7): 770-791.

Palich, L.E., and D.R. Bagby. 1995. Using cognitive theory to explain entrepreneurial risk-taking: Challenging conventional wisdom. Journal of Business Venturing 10 (6): 425-438.

Powell, T.C., D. Lovallo, and C.R. Fox. 2011. Behavioral strategy. Strategic Management Journal 32 (13): 1369-1386.

Shyti, A. 2013. Over-confidence and entrepreneurial choice under ambiguity. HEC Paris Research Paper No. SPE-2013-982.

Simsek, Z., C. Heavey, and J.J.F. Veiga. 2010. The impact of CEO core self-evaluation on the firm's entrepreneurial orientation. Strategic Management Journal 31 (1): 110-119.

Sitkin, S.B., and A.L. Pablo. 1992. Reconceptualizing the determinants of risk behavior. Academy of Management Review 17 (1): 9-38.

Sitkin, S.B., and L.R. Weingart. 1995. Determinants of risky decision-making behavior: A test of the mediating role of risk perceptions and propensity. Academy of Management Journal 38 (6): 1573-1592.

Thornton, G. 2016. Women in business: Turning promise into practice. London: Grant Thornton International.

Tierney, P., and S.M. Farmer. 2002. Creative self-efficacy: Its potential antecedents and relationship to creative performance. Academy of Management Journal 45 (6): 1137-1148.

Trepel, C., C.R. Fox, and R.A. Poldrack. 2005. Prospect theory on the brain? Toward a cognitive neuroscience of decision under risk. Cognitive Brain Research 23 (1): 34-50.

Tversky, A., and C.R. Fox. 1995. Weighing risk and uncertainty. Psychological Review 102 (2): $269-283$.

Tversky, A., and D. Kahneman. 1981. The framing of decisions and the psychology of choice. Science 211 (4481): 453-458.

Tversky, A., and D. Kahneman. 1992. Advances in prospect theory: Cumulative representation of uncertainty. Journal of Risk and uncertainty 5 (4): 297-323.

Tversky, Amos, and Daniel Kahneman. 2000. Choices, values, and frames. Cambridge University Press Wakker, P.P. 2010. Prospect theory: For risk and ambiguity. Cambridge: Cambridge University Press.

Weinstein, N.D., and W.M. Klein. 1996. Unrealistic optimism: Present and future. Journal of Social and Clinical Psychology 15 (1): 1-8.

Publisher's Note Springer Nature remains neutral with regard to jurisdictional claims in published maps and institutional affiliations. 